\title{
Direct renin inhibitor prevents and ameliorates insulin resistance, aortic endothelial dysfunction and vascular remodeling in fructose-fed hypertensive rats
}

\author{
Chu-Lin Chou ${ }^{1,2}$, Cheng-Yong Pang ${ }^{1}$, Tony JF Lee ${ }^{3}$ and Te-Chao Fang ${ }^{1,2,4}$
}

Angiotensin-converting enzyme inhibitors and angiotensin II type 1 receptor blockers can improve insulin resistance and vascular dysfunction in insulin-resistant rats; however, there are few reports on the effects of direct renin inhibitors on these conditions. We investigated the effects of a direct renin inhibitor, aliskiren, on insulin resistance, aortic endothelial dysfunction and vascular remodeling in fructose-fed hypertensive rats. Male Wistar-Kyoto rats were divided into four groups $(\boldsymbol{n}=\mathbf{6}$ per group) and studied for 8 weeks: Group Con: standard chow diet; group Fru: high-fructose diet (60\% fructose); Group FruA: high-fructose diet with concurrent aliskiren treatment $\left(100 \mathrm{mg} \mathrm{kg}^{-1}\right.$ per day); and Group FruB: high-fructose diet with subsequent aliskiren treatment 4 weeks later. Blood was collected for biochemical assays, and isolated rings of the thoracic aorta were obtained for analysis of vascular reactivity, vascular structure and lipid peroxide. Rats fed with high-fructose diets developed significant systolic hypertension, decreased plasma nitrite $\left(\mathrm{NO}_{2}\right.$; nitric oxide metabolite) levels and increased plasma glucose, insulin, triglyceride, total cholesterol and aortic lipid peroxide levels, and aortic wall thickness compared with control rats. Aliskiren treatment, either concurrent or subsequent, elevated plasma $\mathrm{NO}_{2}$ levels and reduced systolic hypertension, insulin resistance, dyslipidemia, aortic lipid peroxide levels and aortic wall hypertrophy in FHR. The peak endothelium-dependent aortic relaxations were significantly higher in rats that received aliskiren treatment than in those that did not. In conclusion, our findings suggest that aliskiren prevents and ameliorates insulin resistance, aortic endothelial dysfunction and oxidative vascular remodeling in fructose-fed hypertensive rats.

Hypertension Research (2013) 36, 123-128; doi:10.1038/hr.2012.124; published online 16 August 2012

Keywords: aliskiren; endothelial dysfunction; insulin resistance; vascular remodeling

\section{INTRODUCTION}

The worldwide increase in the incidence of insulin resistance relates to the increased intake of high-fructose corn syrup. ${ }^{1}$ The excessive intake of fructose can lead to increased insulin resistance and obesity, and subsequently to the development of systemic hypertension. Nevertheless, a high-fructose diet (60\% fructose) in rodents has been demonstrated to cause hypertension as early as 2 weeks after initiation of the diet, as well as causing many features of insulin resistance, including glucose intolerance and hyperlipidemia.. ${ }^{2,3}$ Therefore, the animal model of fructose-fed rats is popularly utilized in the study of insulin resistance and hypertension.

The renin-angiotensin system (RAS) has an important physiological role in the control of body fluids and blood pressure homeostasis, through its effects on cardiovascular and renal functions. Our previous studies demonstrated that angiotensinconverting enzyme inhibitors and angiotensin II type 1 receptor blockers (ARB) reduce blood pressure and improve insulin sensitivity in hyperinsulinemia-induced hypertensive rats, ${ }^{4,5}$ indicating that the inhibition of RAS may contribute to the amelioration of insulin resistance. A novel direct renin inhibitor, aliskiren, has been demonstrated to reduce blood pressure in spontaneously hypertensive rats, ${ }^{6}$ essential hypertensive patients, ${ }^{7}$ and patients with type 2 diabetes. ${ }^{8}$ Our recent study showed that aliskiren not only reversed hypertension but also improved hyperglycemia and dyslipidemia in fructose-fed hypertensive rats. ${ }^{9}$ Moreover, the RAS has a key role in vascular dysfunction and remodeling, subsequently leading to cardiovascular morbidity and mortality. However, the effects of direct renin inhibitors on vascular endothelial function and vascular remodeling have remained unclear. The aim of this study was to evaluate the efficacy of aliskiren concerning insulin resistance, aortic endothelial dysfunction and vascular remodeling in fructose-fed hypertensive rats.

\footnotetext{
${ }^{1}$ Institute of Medical Sciences, Buddhist Tzu Chi University, Hualien, Taiwan; ${ }^{2}$ Division of Nephrology, Buddhist Tzu Chi General Hospital, Hualien, Taiwan; ${ }^{3}$ Institutes of Life Sciences, Pharmacology and Toxicology, and Medical Sciences, Buddhist Tzu Chi University, Hualien, Taiwan and ${ }^{4}$ Department of Medicine, Medical College, Tzu Chi University, Hualien, Taiwan

Correspondence: Dr T-C Fang, Division of Nephrology, Buddhist Tzu Chi General Hospital, 707, Section 3, Chung Yang Road, Hualien 97004, Taiwan.

E-mail: fangtechao@yahoo.com.tw

Received 10 May 2012; revised 19 June 2012; accepted 22 June 2012; published online 16 August 2012
} 


\section{METHODS}

\section{Animals}

All experimental procedures were carried out with the prior approval of the Institutional Animal Care and Use Committee of Tzu Chi University (protocol number: 98-05) and according to the Guide for the Care and Use of Laboratory Animals. Male Wistar-Kyoto rats, initially weighing 200-230 g, were used for the experiments. Rats were placed in metabolic cages and were kept in a room with air maintained at a temperature of $24-27^{\circ} \mathrm{C}$, a humidity of $50-80 \%$ and a $12-\mathrm{h}$ light/dark cycle, and had access to tap water ad libitum throughout the experiments.

The standard chow diet was composed of $50 \%$ starch, $21 \%$ protein, $4 \%$ fat, $4.5 \%$ cellulose and standard vitamins and mineral mix. The high-fructose diet (Harlan Teklad, Madison, WI, USA) was composed of $60 \%$ fructose, $21 \%$ protein, $5 \%$ fat, $8 \%$ cellulose and standard vitamins and mineral mix.

\section{Experimental protocols}

After a control period of 1 week, rats were divided into four groups ( $n=6$ for each group). Rats were fed as follows: Group Con: rats were fed standard chow diet for 8 weeks and served as the control group; Group Fru: rats were fed the high-fructose diet for 8 weeks; Group FruA: rats were fed the high-fructose diet and were co-infused with aliskiren $\left(100 \mathrm{mg} \mathrm{kg}^{-1}\right.$ per day; a kind gift of Novartis Pharmaceuticals, Basel, Switzerland) via a s.c. osmotic minipump for 8 weeks; and Group FruB: rats were treated as Group Fru, but aliskiren ( $100 \mathrm{mg} \mathrm{kg}^{-1}$ per day) was administered 4 weeks later. The first day of fructose feeding were recognized as day 1 . Body weight and daily urine amount were measured twice a week. Systolic blood pressure (SBP) was measured twice a week by the tail-cuff method. Blood samples $(1 \mathrm{ml})$ for glucose, insulin, triglycerides, total cholesterol and nitrite $\left(\mathrm{NO}_{2}\right)$ were taken after $12 \mathrm{~h}$ of fasting at day 0 , at the midpoint (day 28) and at the end of the study (day 56), from the femoral artery or heart under adequate anesthesia. Rats were i.p. anesthetized with ketamine $\left(60 \mathrm{mg} \mathrm{kg}^{-1}\right.$, IP) and xylazine $\left(7.5 \mathrm{mg} \mathrm{kg}^{-1}\right.$, IP) at day 0 and day 28 , and sodium pentobarbital $\left(40 \mathrm{mg} \mathrm{kg}^{-1}\right)$ at day 56 . At day 56 the rats were killed by exsanguination, including blood collection from the heart, and their tissues were quickly collected under deep anesthesia. Plasma was separated, divided into aliquots and frozen until analysis.

\section{SBP measurements}

Rats were removed from the animal room and were taken to the laboratory at 0800 hours; they were allowed free access to water and were kept in a quiet area before SBP was measured at 0900 hours. The tail-cuff method without heating was used to measure SBP with the use of a programmed electrosphygmomanometer (MK-2000ST, Muromachi, Tokyo, Japan) as described previously. ${ }^{4,5,9}$ The mean of six consecutive readings was used as the value of SBP for each rat for that day, and SBP was determined twice a week during the control (1 week) and experimental (8 weeks) periods.

\section{Osmotic minipump installation}

The osmotic minipump installation was carried out as described in our previous studies. ${ }^{4,5,9}$ In brief, when aliskiren was administered to rats, an osmotic minipump (no. 2002, 14 days of active life, Alza Corp, Vacaville, CA, USA) was filled with the agent, which was dissolved in normal saline, and was implanted s.c. in rats under brief anesthesia with ketamine $\left(60 \mathrm{mg} \mathrm{kg}^{-1}\right.$, IP) and xylazine ( $7.5 \mathrm{mg} \mathrm{kg}^{-1}$, IP). Aqueous penicillin $\left(5000 \mathrm{U} \mathrm{kg}^{-1} \mathrm{SC}\right)$ was administered immediately after minipump implantation.

\section{Homeostatic model assessment-insulin resistance (HOMA-IR) and oral glucose tolerance test}

Insulin resistance was assessed via HOMA-IR, and was determined at day 0, day 28 and day 56. HOMA-IR was calculated using this formula: [plasma glucose $\left(\mathrm{mmoll}^{-1}\right) \times$ insulin $\left.\left(\mu \mathrm{IU} \mathrm{ml}^{-1}\right)\right] / 22.5$.

In addition, an oral glucose tolerance test was performed at day 55. After $12 \mathrm{~h}$ of fasting, $0.1 \mathrm{ml}$ blood was taken from the tail vein and plasma glucose was measured using Accu-Check Advantage Blood Glucose Monitor (Roche Diagnostic Corporation, Indianapolis, IN, USA). Immediately after this baseline measurement, $1 \mathrm{ml}$ per $100 \mathrm{~g}$ body weight of a $50 \%\left(\mathrm{wt} \mathrm{vol}^{-1}\right)$ solution of glucose was administered using gastric gavages by the method of Navarro-Cid et al. ${ }^{10}$ Plasma glucose level was measured 0, 30, 60, 90 and $120 \mathrm{~min}$ after the glucose load.

\section{Laboratory measurements}

The blood samples were immediately centrifuged at $4000 \mathrm{~g}$ at $4{ }^{\circ} \mathrm{C}$ for $10 \mathrm{~min}$. The plasma samples were separated and used for immediate assays of glucose, insulin, triglycerides and total cholesterol. Plasma triglycerides and total cholesterol were determined by standard methods using a COBAS Integra 800 analyzer (Roche Diagnostics). Plasma glucose was measured using AccuCheck Advantage Blood Glucose Monitor (Roche Diagnostic Corporation). Plasma insulin was measured using a rat/mouse insulin enzyme immunoassay kit (EZRMI-13 K, Millipore, St Charles, MO, USA).

\section{Griess nitrite assay}

$\mathrm{NO}_{2}$, nitric oxide (NO) metabolite, was measured by a method employing Griess' reagent (Sigma-Aldrich, St Louis, MO, USA). To measure the $\mathrm{NO}_{2}$ content, $100 \mu \mathrm{l}$ of plasma was incubated with $100 \mu \mathrm{l}$ of Griess reagent at room temperature for $10 \mathrm{~min}$. Following this, the absorbance of the solution was determined at $540 \mathrm{~nm}$ with a microplate reader, Biotrak II (GE Healthcare, Buckinghamshire, UK). The $\mathrm{NO}_{2}$ content was calculated based on a standard curve constructed with $\mathrm{NaNO}_{2}$.

\section{In vitro vascular reactivity}

Evaluation of in vitro vascular reactivity was performed as described in our previous study. ${ }^{11}$ The thoracic aorta were dissected and aortic ring segments ( $3 \mathrm{~mm}$ in length) were suspended in individual organ chambers filled with oxygenated $\left(95 \% \mathrm{O}_{2}\right.$ and $\left.5 \% \mathrm{CO}_{2}\right)$ Krebs' buffer solution maintained at $37^{\circ} \mathrm{C}$. Krebs solution consisted of $117 \mathrm{mmoll}^{-1} \mathrm{NaCl}, 25 \mathrm{mmoll}^{-1} \mathrm{NaHCO}_{3}$, $4.7 \mathrm{mmoll}^{-1} \mathrm{KCl}, 2.5 \mathrm{mmoll}^{-1} \mathrm{CaCl}_{2}, 1.2 \mathrm{mmoll}^{-1} \mathrm{MgSO}_{4}, 1.2 \mathrm{mmoll}^{-1}$ $\mathrm{KH}_{2} \mathrm{SO}_{4}, 11.1 \mathrm{mmoll}^{-1}$ glucose and $0.28 \mathrm{mmoll}^{-1}$ ascorbic acid at $\mathrm{pH}$ 7.4. Tension changes in the aortic ring were recorded by using an isometric transducer (FT03C; Grass, West Warwick, RI, USA) connected to a Grass polygraph. The active muscle tone of ring segments were then appropriately contracted by phenylephrine. After a stable contraction plateau was reached, relaxation of the aortic rings was measured in response to cumulative additions of acetylcholine (ACh, Sigma; $10-9$ to $10-4 \mathrm{moll}^{-1}$ ). After the last vasodilator response to acetylcholine, a single dose of NG-nitro-L-arginine methyl ester (L-NAME; $100 \mathrm{nmol}$ ), a NO synthesis inhibitor, was given. When a steady contraction in response to L-NAME was reached, vasodilator response to sodium nitroprusside (Riedel-deHaen, Seelze, Germany; $10-9$ to $10-4 \mathrm{moll}^{-1}$ ) was evaluated.

\section{Remodeling of the aortic wall}

Briefly, 3- $\mu \mathrm{m}$ thick paraffin-embedded specimens of thoracic aorta were stained with hematoxylin-eosin and Masson's trichrome stain, which indicates regions of fibrosis. Vascular wall thickness was measured as an indicator of structural abnormalities of the aorta. Histopathology and morphometry was performed by investigators who were blinded to the treatment being administered.

\section{Analysis of oxidative stress marker}

The lipid peroxide level, a marker for oxidative stress, in the thoracic aortic tissue was assessed by measuring thiobarbituric acid-reactive substances using a commercially available kit (Cell Biolabs, San Diego, CA, USA). Thiobarbituric acid-reactive substances values were expressed as nmol mg ${ }^{-1}$ of protein.

\section{Statistical analysis}

All results were expressed as mean \pm s.d. Experimental data over time were compared between groups by two-way analysis of variance. When a significant effect was detected by analysis of variance, the Newman-Keuls test was used to establish statistically significant differences between means. The Student's $t$-test for unpaired data was also performed when appropriate. A value of $P<0.05$ was considered statistically significant. 


\section{RESULTS}

Aliskiren prevents and ameliorates systolic hypertension in fructose-fed rats

Changes in SBP of control and fructose-fed rats, with or without aliskiren treatment, are shown in Figure 1. High-fructose feeding caused a significant rise in SBP from the baseline value of $108 \pm 3$ to $141 \pm 5$ and $140 \pm 4 \mathrm{~mm} \mathrm{Hg}$ at day 28 and day 56, respectively. Concurrent and subsequent aliskiren treatment prevented and reversed the rise in SBP in fructose-fed rats, which had SBP values similar to those of control rats.

Aliskiren does not alter food intake, body weight gain, water intake or urine flow in fructose-fed rats

Food intake, body weight gain, water intake and urine flow did not differ between the various groups throughout the entire study period (see Supplementary Material, Supplementary Figure S1).

Aliskiren averts and improves hyperglycemia, hyperinsulinemia, hypertriglyceridemia and hypercholesterolemia in fructose-fed rats The effects of a high-fructose diet alone and in combination with aliskiren treatment on plasma glucose, insulin, triglyceride and total cholesterol levels are summarized in Table 1. High-fructose feeding significantly increased plasma glucose, insulin, triglyceride and total cholesterol levels compared with those seen in control rats throughout the course of the study. Concurrent and subsequent aliskiren treatment ameliorated the rise in plasma glucose, insulin, triglyceride and total cholesterol levels in the fructose-fed rats.

Aliskiren overwhelms and ameliorates insulin resistance and glucose intolerance in fructose-fed rats

The effects of aliskiren on the HOMA-IR and oral glucose tolerance test results of fructose-fed rats are shown in Figure 2. The levels of

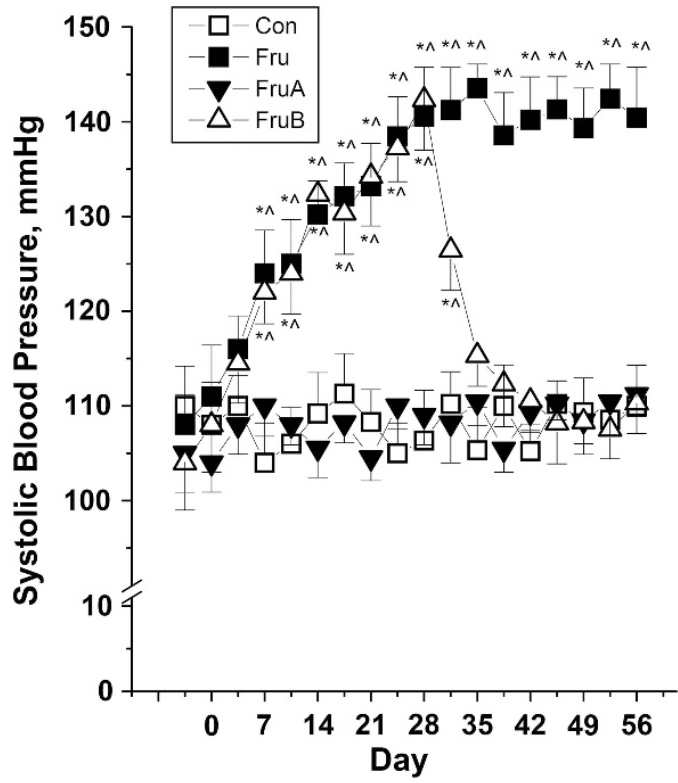

Figure 1 Variations in systolic blood pressure in control and fructose-fed rats with or without aliskiren treatment. Con: control rats with normal chow diet; Fru: fructose-fed diet; FruA: fructose-fed diet with concurrent aliskiren administration; FruB: fructose-fed diet with subsequent aliskiren administration 4 weeks later. Values are mean \pm s.d. * and $\wedge$ denote $P<0.05$ vs. pre-fructose and control rats, respectively. $N=6$ for each group.
HOMA-IR in fructose-fed rats with concurrent 8-week or subsequent 4-week aliskiren treatment ameliorated the increase in HOMA-IR levels, or reverted higher HOMA-IR levels to the control level, respectively. Moreover, the responses of plasma glucose levels to oral glucose loading were significantly greater in fructose-fed rats than in standard diet-fed rats (Figure 2B). Plasma glucose levels following oral glucose loading were meaningfully lower in aliskiren-treated rats in groups FruA and FruB than in those in the Fru group, indicative of ameliorated glucose intolerance.

Aliskiren improves endothelium dysfunction and increases plasma $\mathrm{NO}_{2}$ levels in fructose-fed rats

The effect of aliskiren on relaxing responses to acetylcholine and sodium nitroprusside in fructose-fed rats with or without aliskiren treatment is shown in Figure 3. The peak aortic relaxation in response to acetylcholine in group FruA and FruB was significantly higher than in group Fru $(71.24 \pm 4.26$ and $70.97 \pm 4.6$ vs. $52.83 \pm 3.35 \%$, respectively; $P<0.05$ ). On the other hand, relaxation produced by sodium nitroprusside was not significantly different between these groups. Changes in plasma $\mathrm{NO}_{2}$ concentrations, NO metabolite, in fructose-fed rats with or without aliskiren treatment are shown in Figure 4. Concurrent or subsequent aliskiren treatment resulted in higher plasma $\mathrm{NO}_{2}$ levels than those in fructose-fed rats, suggesting that aliskiren has the ability to stimulate NO release.
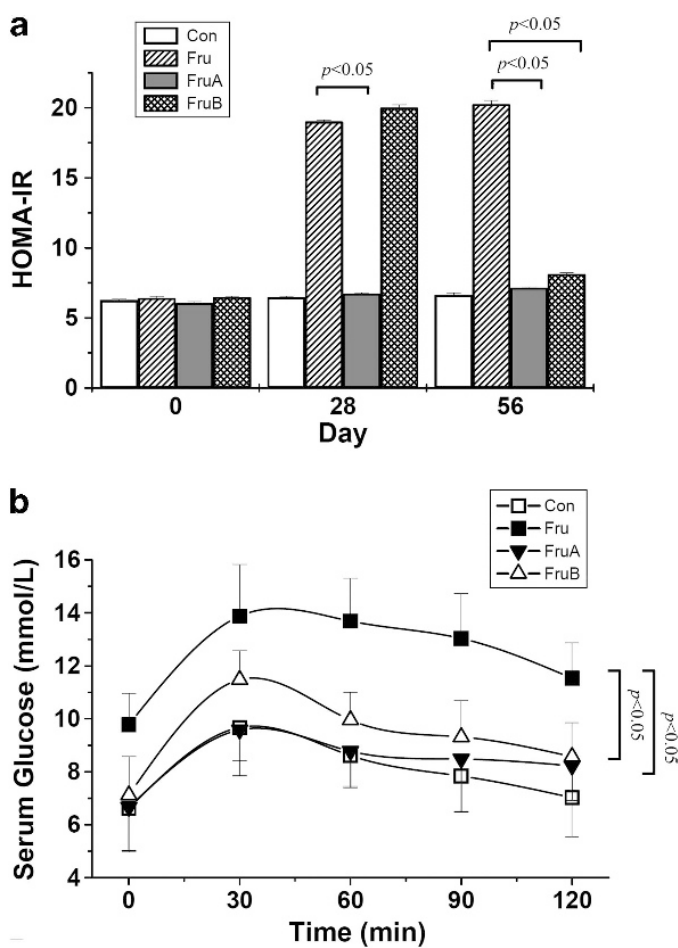

Figure 2 Effect of aliskiren on insulin resistance (a) and blood glucose curves following an oral glucose loading at day 56 (b) in rats receiving the control and high-fructose diets. Con: control rats with normal chow diet; Fru: fructose-fed diet; FruA: fructose-fed diet with concurrent aliskiren administration; FruB: fructose-fed diet with subsequent aliskiren administration 4 weeks later. HOMA-IR, homeostasis model assessment of insulin resistance. Values are mean \pm s.d. $N=6$ for each group. 
Table 1 Effects of a high-fructose diet, alone and in combination with aliskiren, on changes of plasma biochemistries

\begin{tabular}{|c|c|c|c|c|c|c|c|c|c|c|c|c|}
\hline \multirow[b]{2}{*}{ Group } & \multicolumn{4}{|c|}{ Day 0} & \multicolumn{4}{|c|}{ Day 28} & \multicolumn{4}{|c|}{ Day 56} \\
\hline & Con & Fru & FruA & FruB & Con & Fru & FruA & FruB & Con & Fru & FruA & FruB \\
\hline Glucose (mmol ${ }^{-1}$ ) & $6.28 \pm 0.6$ & $6.32 \pm 0.7$ & $6.24 \pm 0.8$ & $6.30 \pm 0.5$ & $6.31 \pm 0.5$ & $10.2 \pm 0.7^{*, * *}$ & $6.42 \pm 0.4$ & $10.5 \pm 1.3^{*, * *}$ & $6.62 \pm 0.8$ & $10.7 \pm 1.5^{*, * *}$ & $6.88 \pm 0.2$ & $7.1 \pm 0.6$ \\
\hline Insulin (pmol I-1) & $155 \pm 24$ & $158 \pm 28$ & $151 \pm 25$ & $161 \pm 22$ & $160 \pm 20$ & $291 \pm 29^{*, * *}$ & $164 \pm 24$ & $298 \pm 27^{*, * *}$ & $156 \pm 30$ & $296 \pm 27^{*, * *}$ & $163 \pm 28$ & $178 \pm 22$ \\
\hline $\mathrm{TG}\left(\mathrm{mmol} \mathrm{I}^{-1}\right)$ & $1.50 \pm 0.1$ & $1.56 \pm 0.1$ & $1.60 \pm 0.2$ & $1.58 \pm 0.3$ & $1.62 \pm 0.1$ & $3.22 \pm 0.3^{*, * *}$ & $1.60 \pm 0.2$ & $3.11 \pm 0.3^{*, * *}$ & $1.58 \pm 0.1$ & $3.26 \pm 0.2^{*, * *}$ & $1.78 \pm 0.3$ & $1.70 \pm 0.2$ \\
\hline
\end{tabular}

Abbreviations: Con, control rats with normal chow diet; Fru, fructose-fed diet; FruA, fructose-fed diet with concurrent aliskiren administration; FruB, fructose-fed diet with subsequent aliskiren administration 4 weeks later; TG, Triglycerides; TC, Total cholesterol.

Values are mean \pm s.d.

${ }^{*} P<0.05$ vs. day $0 ;{ }^{* *} P<0.05$ vs control group.
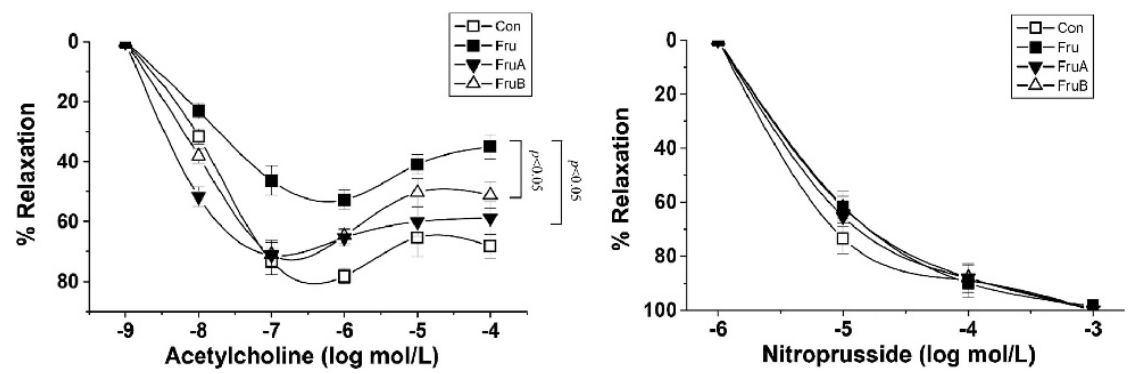

Figure 3 Endothelium-dependent vascular relaxations in response to acetylcholine and endothelium-independent sodium nitroprusside (SNP) in thoracic aortic segments, 8 weeks after feeding the control or high-fructose diets, with or without aliskiren. Con: control rats with normal chow diet; Fru: fructose-fed diet; FruA: fructose-fed diet with concurrent aliskiren administration; FruB: fructose-fed diet with subsequent aliskiren administration 4 weeks later. Vessels were studied as ring segments in organ chambers, and relaxations in response to acetylcholine (Ach) and SNP were measured. Values are mean \pm s.d. $N=6$ for each group.

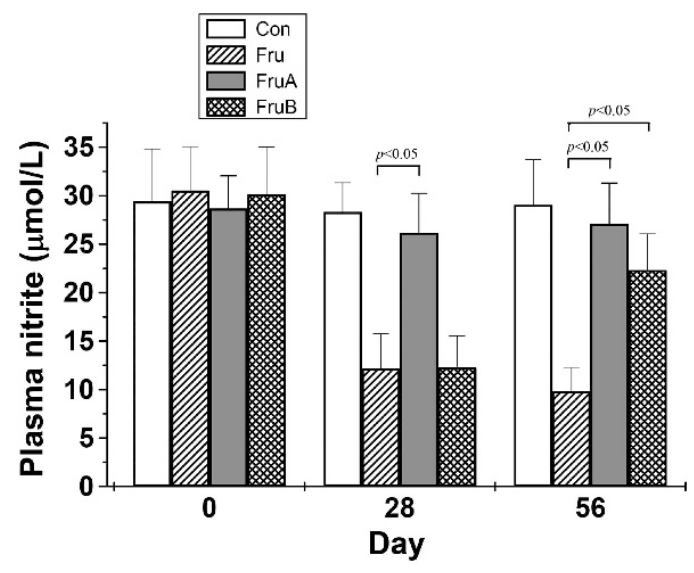

Figure 4 Plasma Nitrite concentrations, NO metabolite, in control rats and fructose-fed rats with or without aliskiren treatment. Con: control rats with normal chow diet; Fru: fructose-fed diet; FruA: fructose-fed diet with concurrent aliskiren administration; FruB: fructose-fed diet with subsequent aliskiren administration 4 weeks later. Values are mean \pm s.d. $N=6$ for each group.

\section{Aliskiren averts and ameliorates aortic wall remodeling and oxidative stress in fructose-fed rats}

The effects of aliskiren on aortic wall remodeling and lipid peroxide levels in fructose-fed rats are presented in Figure 5. Vascular wall hypertrophy was reduced by either concurrent 8-week or subsequent 4 -week aliskiren treatment, relative to that seen with the high-fructose diet without any aliskiren treatment (aortic wall thickness from $135 \pm 6$ to $108 \pm 8$ and $115 \pm 5 \%$, respectively; $P<0.05$ ). Additionally, rats on high-fructose diets exhibited higher lipid peroxide levels in the aorta compared with control rats, and concurrent or subsequent aliskiren treatment decreased lipid peroxide levels compared with those seen in rats on a high-fructose diet (from $1.85 \pm 0.18$, to $1.35 \pm 0.12$ and $1.43 \pm 0.16 \mathrm{nmol} \mathrm{mg}^{-1}$ protein, respectively; $P<0.05$ ).

\section{DISCUSSION}

In this rat model, we have established that a $60 \%$ fructose diet causes systolic hypertension, diminishes plasma $\mathrm{NO}_{2}$ levels and increases plasma glucose, insulin, triglyceride, total cholesterol and aortic lipid peroxide levels, similar to prior reports by others. ${ }^{12-15}$ The wellestablished rat models concerning the dose-dependent effects of aliskiren have indicated that aliskiren at a high dose of $100 \mathrm{mg} \mathrm{kg}^{-1}$ per day lowers blood pressure in hypertensive rats ${ }^{7}$ and myocardial infarction rats. ${ }^{18}$ Therefore, the effects of $100 \mathrm{mg} \mathrm{kg}^{-1}$ aliskiren per day were investigated in our study. Moreover, we report that aliskiren, a novel direct renin inhibitor, can prevent and ameliorate the progress of insulin resistance, glucose intolerance, dyslipidemia, hypertension, $\mathrm{NO}$-dependent endothelial dysfunction and oxidative aortic wall remodeling in fructose-fed rats, suggesting that renin-mediated pathways have a key role in minimizing insulin resistance and hypertensive vascular disorders.

More recently, the RAS in fructose-fed rats has been shown to have a cardinal role in the pathogenesis of hypertension and vascular dysfunction. ${ }^{16,17}$ Previous studies showed that fructose feeding in rats resulted in the elevation of plasma angiotensin II and increased the activity of the tissue angiotensin II type 1 receptor, caused high blood 
a

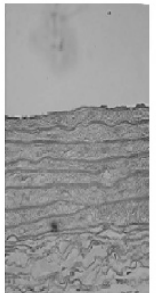

Con
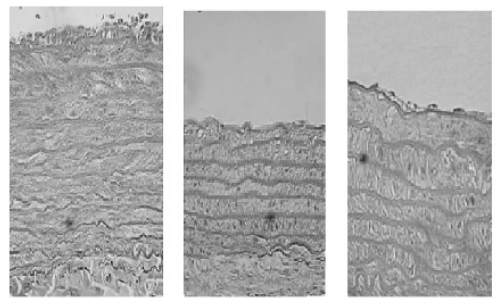

Fru

FruA

FruB
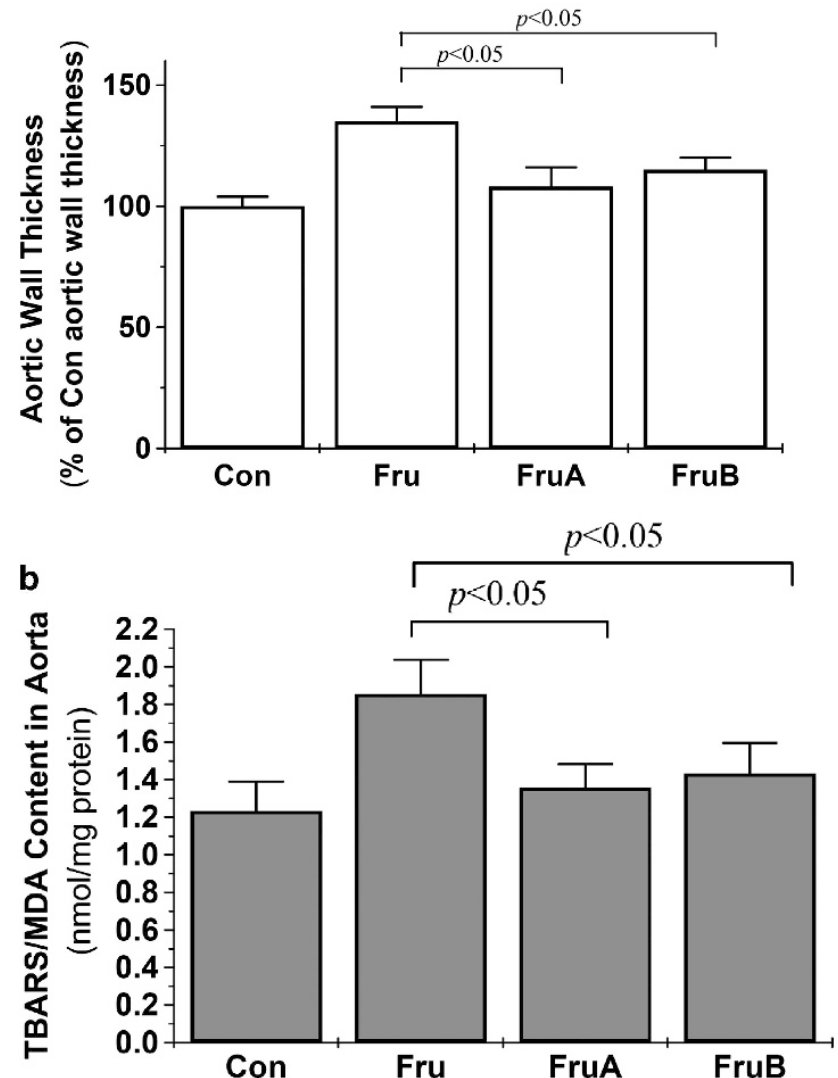

Figure 5 Effects of aliskiren on vascular remodeling (a) and lipid peroxide levels through thiobarbituric acid-reactive substances (TBARS) measurement in the thoracic aorta (b) in fructose-fed rats, measured by Masson trichrome staining of aorta. Con: control rats with normal chow diet; Fru: fructose-fed diet; FruA: fructose-fed diet with concurrent aliskiren administration; FruB: fructose-fed diet with subsequent aliskiren administration 4 weeks later. Aliskiren significantly reduced the aortic wall thickness and lipid peroxide levels in high-fructose-fed rats. Original magnification $\times 40$. Values are mean \pm s.d. $N=6$ for each group. A full color version of this figure is available at the Hypertension Research journal online.

pressure, impaired endothelial NO synthase and caused vascular dysfunction. ${ }^{16-18}$ Administration of an angiotensin-converting enzyme inhibitor or ARB treatment has been demonstrated to decrease blood pressure and to restore the activity of endothelial NO synthase in fructose-fed rats. ${ }^{18,19}$ Furthermore, recent study reported aliskiren (100 $\mathrm{mg} \mathrm{kg}^{-1}$ per day) treatment with blood pressure lowering effects had improved coronary endothelial function and decreased cardiac hypertrophy in spontaneously hypertensive rats, ${ }^{20}$ which was similar to ours. In this study, we report that aliskiren $\left(100 \mathrm{mg} \mathrm{kg}^{-1}\right.$ per day) with blood pressure lowering properties could ameliorate the rise in SBP and the decline of plasma $\mathrm{NO}_{2}$, and induce vascular relaxation in fructose-fed rats, and that even vascular relaxation impaired by a preceding highfructose diet could be improved by aliskiren treatment. In a clinical study, aliskiren could increase NO availability of the forearm arterioles in essential hypertensive patients, derived from an antioxidant activity. ${ }^{21}$ Besides, a recent study has indicated that the larger increase in renin during renin inhibition could overwhelm (pro)renin receptor expression, and has a greater suppression of (pro)renin receptor-mediated effects than other renin-Ang blockers. ${ }^{22}$ For example, renal (pro)renin receptor expression was decreased by aliskiren treatment in hypertensive rats with ischemic kidneys. ${ }^{23}$ The protective effects in our study may be mediated through the decrease in blood pressure and the inhibition of renin-mediated effect. These data suggest that a direct renin inhibitor can protect fructose-fed rats from upregulated renin activity and impaired $\mathrm{NO}$-dependent vascular relaxation.

Activity of the RAS could mediate vascular remodeling and oxidative stress to induce secondary hypertension and cardiovascular diseases in fructose-fed rats. ${ }^{16,17,24}$ In this study, we tested and confirmed the ability of aliskiren treatment to protect the aortic wall from vascular remodeling and oxidative stress and to minimize fructose-mediated vascular damage in fructose-fed rats. Aliskiren can improve cardiac hypertrophy not only in diabetic mice but also in hypertensive rats. For example, aliskiren had the direct cardiac effects to suppress cardiac hypertrophy through the attenuation of oxidative stress in endothelial NO synthase-deficient mice or in diabetic mice. ${ }^{25,26}$ The other studies showed that aliskiren lessens cardiac hypertrophy through diminished systemic renin/angiotensin II activity and myocardial NADPH oxidase activity in hypertensive rats, ${ }^{20,27}$ consistent with the results of our study. Recently, the role of oxidative stress has been emphasized and has been shown to mediate fructose-induced vascular remodeling. ${ }^{24,28}$ In fructose-fed rats, we have observed that oxidative stress and vascular remodeling can be diminished by inhibiting renin activity.

Our results showed that inhibition of renin activity by aliskiren can ameliorate insulin resistance and glucose intolerance in fructose-fed rats, consistent with the results of two other studies, ${ }^{29,30}$ indicating that renin inhibition is associated with increased pancreatic islet function and upregulation of insulin action on skeletal muscle glucose transport, and that these effects can improve insulin resistance and glucose intolerance by decreasing the function of tissue angiotensin II and angiotensin II type 1 receptor. Besides, in our study, the direct renin inhibitor not only prevents but also reverses dyslipidemia to well lipid profiles, comparable to recent aliskiren studies on improvement of raised total cholesterol and triglyceride levels in models of insulin resistance. ${ }^{31,32}$ Results of other studies on the effects of angiotensinconverting enzyme inhibitors and ARB on fructose-fed rats were also similar to the data in our study. ${ }^{33-35}$ Reported mechanisms suggested that ARBs partially activate peroxisome proliferator-activated receptor gamma to improve insulin sensitivity and reduce serum triglyceride levels and hepatic triglyceride accumulation. ${ }^{36-38}$

In conclusion, our data suggest that a direct renin inhibitor, aliskiren, not only prevents but also reverses the progress of insulin resistance, glucose intolerance, dyslipidemia, hypertension, NOdependent endothelial dysfunction and oxidative aortic wall remodeling in fructose-fed rats. In the future, the benefits of aliskiren-related benefits on other organs diseases in insulin-resistance conditions merit further investigation.

\section{CONFLICT OF INTEREST}

The authors declare no conflict of interest. 


\section{ACKNOWLEDGEMENTS}

This work was supported by a grant from Taiwan Society of Nephrology for providing 2010 Research Grants (TSN-2010-01) for this study. This study was presented at the 2012 Congress of the European Renal Association-European Dialysis and Transplant Association (Paris, France, May 24-27, 2012).

1 Johnson RJ, Segal MS, Sautin Y, Nakagawa T, Feig DI, Kang DH, Gersch MS, Benner S, Sanchez-Lozada LG. Potential role of sugar (fructose) in the epidemic of hypertension, obesity and the metabolic syndrome, diabetes, kidney disease, and cardiovascular disease. Am J Clin Nutr 2007; 86: 899-906.

2 Hwang IS, Ho H, Hoffman BB, Reaven GM. Fructose-induced insulin resistance and hypertension in rats. Hypertension 1987; 10: 512-516.

3 Giacchetti G, Sechi LA, Griffin CA, Don BR, Mantero F, Schambelan M. The tissue renin-angiotensin system in rats with fructose-induced hypertension: overexpression of type 1 angiotensin II receptor in adipose tissue. J Hypertens 2000; 18: 695-702.

4 Fang TC, Huang WC. Angiotensin receptor blockade blunts hyperinsulinemia-induced hypertension in rats. Hypertension 1998; 32: 235-242.

5 Fang TC, Huang WC. Role of angiotensin II in hyperinsulinemia-induced hypertension in rats. J Hypertens 1998; 16: 1767-1774.

6 Wood JM, Schnell CR, Cumin F, Menard J, Webb RL. Aliskiren a novel, orally effective renin inhibitor, lowers blood pressure in marmosets and spontaneously hypertensive rats. J Hypertens 2005; 23: 417-426.

7 Yarows SA, Oparil S, Patel S, Fang H, Zhang J. Aliskiren and valsartan in stage 2 hypertension: subgroup analysis of a randomized, double-blind study. Adv Ther 2008; 25: $1288-1302$.

8 Parving $\mathrm{HH}$, Persson F, Lewis JB, Lewis EJ, Hollenberg NK. Aliskiren combined with losartan in type 2 diabetes and nephropathy. N Engl J Med 2008; 358: 2433-2446.

9 Chou CL, Lai YH, Lin TY, Lee TJF, Fang TC. Aliskiren prevents and ameliorates metabolic syndrome in fructose-fed rats. Arch Med Sci 2011: 7: 882-888.

10 Navarro-Cid J, Maeso R, Perez-Vizcaino F, Cachofeiro V, Ruilope LM, Tamargo J, Lahera V. Effects of losartan on blood pressure, metabolic alterations, and vascular reactivity in the fructose-induced hypertensive rat. Hypertension 1995; 26: 1074-1078.

11 Lin HW, Liu CZ, Cao D, Chen PY, Chen MF, Lin SZ, Mozayan M, Chen AF, Premkumar LS, Torry DS, Lee TJ. Endogenous methyl palmitate modulates nicotinic receptormediated transmission in the superior cervical ganglion. Proc Natl Acad Sci USA 2008; 105: 19526-19531.

12 Huang BW, Chiang MT, Yao HT, Chiang W. The effect of high-fat and high-fructose diets on glucose tolerance and plasma lipid and leptin levels in rats. Diabetes Obes Metab 2004; 6: 120-126.

13 Nakagawa T, Hu H, Zharikov S, Tuttle KR, Short RA, Glushakova O, Ouyang X, Feig DI, Block ER, Herrera-Acosta J, Patel JM, Johnson RJ. A causal role for uric acid in fructose-induced metabolic syndrome. Am J Physiol Renal Physiol 2006; 290 F625-F631.

14 Reungjui S, Roncal CA, Mu W, Srinivas TR, Sirivongs D, Johnson RJ, Nakagawa T. Thiazide diuretics exacerbate fructose-induced metabolic syndrome. J Am Soc Nephrol 2007; 18: 2724-2731.

15 Nagai Y, Ichihara A, Nakano D, Kimura S, Pelisch N, Fujisawa Y, Hitomi H, Hosomi N Kiyomoto H, Kohno M, Ito H, Nishiyama A. Possible contribution of the non-proteolytic activation of prorenin to the development of insulin resistance in fructose-fed rats. Exp Physiol 2009; 94: 1016-1023.

16 Shinozaki K, Ayajiki K, Nishio Y, Sugaya T, Kashiwagi A, Okamura T. Evidence for a causal role of the renin-angiotensin system in vascular dysfunction associated with insulin resistance. Hypertension 2004; 43: 255-262.

17 Nyby MD, Abedi K, Smutko V, Eslami P, Tuck ML. Vascular Angiotensin type 1 receptor expression is associated with vascular dysfunction, oxidative stress and inflammation in fructose-fed rats. Hypertens Res 2007; 30: 451-457.

18 Miatello R, Risler N, Castro C, Cruzado M, Gonzalez S, Zumino AP. Chronic administration of losartan reverses cardiovascular changes in hypertensive fructosefed rats. Cell Mol Biol 2003; 49: 945-952.
19 Miatello R, Risler N, Gonzalez S, Castro C, Ruttler M. Cruzado M. Effects of enalapril on the vascular wall in an experimental model of syndrome X. Am J Hypertens 2002 15: 872-878.

20 van Esch JH, Moltzer E, van Veghel R, Garrelds IM, Leijten F, Bouhuizen AM, Danser $\mathrm{AH}$. Beneficial cardiac effects of the renin inhibitor aliskiren in spontaneously hypertensive rats. J Hypertens 2010; 28: 2145-2155.

21 Virdis A, Ghiadoni L, Qasem AA, Lorenzini G, Duranti E, Cartoni G, Bruno RM, Bernini G, Taddei S. Effect of aliskiren treatment on endothelium-dependent vasodilation and aortic stiffness in essential hypertensive patients. Eur Heart J 2012; 33: 1530-1538.

22 Danser $\mathrm{AH}$. The increase in renin during renin inhibition: does it result in harmful effects by the (pro)renin receptor? Hypertens Res 2010; 33: 4-10.

23 Sun CY, Cherng WJ, Jian HZ, Hsu HH, Wu IW, Hsu HJ, Wu MS. Aliskiren reduced rena fibrosis in mice with chronic ischemic kidney injury-beyond the direct renin inhibition. Hypertens Res 2012; 35: 304-311.

24 Risler NR. Cruzado MC, Miatello RM. Vascular remodeling in experimental hypertension. Scientific World Journal 2005; 5: 959-971.

25 Yamamoto E, Kataoka K, Dong YF, Nakamura T, Fukuda M, Tokutomi Y, Matsuba S, Nako H, Nakagata N, Kaneko T, Ogawa H, Kim-Mitsuyama S. Aliskiren enhances the protective effects of valsartan against cardiovascular and renal injury in endothelia nitric oxide synthase-deficient mice. Hypertension 2009; 54: 633-638.

26 Dong YF, Liu L, Kataoka K, Nakamura T, Fukuda M, Tokutomi Y, Nako H, Ogawa H, Kim-Mitsuyama S. Aliskiren prevents cardiovascular complications and pancreatic injury in a mouse model of obesity and type 2 diabetes. Diabetologia 2010; 53 180-191.

27 Whaley-Connell A, Habibi J, Cooper SA, Demarco VG, Hayden MR, Stump CS, Link D, Ferrario CM, Sowers JR. Effect of renin inhibition and AT1R blockade on myocardia remodeling in the transgenic Ren2 rat. Am J Physiol Endocrinol Metab 2008; 295: E103-E109.

28 Delbosc S, Paizanis E, Magous R, Araiz C, Dimo T, Cristol JP, Cros G, Azay J. Involvement of oxidative stress and NADPH oxidase activation in the development of cardiovascular complications in a model of insulin resistance, the fructose-fed rat. Atherosclerosis 2005; 179: 43-49.

29 Habibi J, Whaley-Connell A, Hayden MR, DeMarco VG, Schneider R, Sowers SD, Karuparthi P, Ferrario CM, Sowers JR. Renin inhibition attenuates insulin resistance, oxidative stress, and pancreatic remodeling in the transgenic Ren2 rat. Endocrinology 2008; 149: 5643-5653.

30 Lastra G, Habibi J, Whaley-Connell AT, Manrique C, Hayden MR, Rehmer J, Patel K, Ferrario $\mathrm{C}$, Sowers JR. Direct renin inhibition improves systemic insulin resistance and skeletal muscle glucose transport in a transgenic rodent model of tissue renin overexpression. Endocrinology 2009; 150: 2561-2568.

31 Iwai M, Kanno H, Tomono Y, Inaba S, Senba I, Furuno M, Mogi M, Horiuchi M. Direct renin inhibition improved insulin resistance and adipose tissue dysfunction in type 2 diabetic KK-A(y) mice. J Hypertens 2010; 28: 1471-1481.

32 Rashikh A, Abul Kalam N, Akhtar M, Mahmood D, Pillai KK, Ahmad SJ. Protective effects of aliskiren in doxorubicin-induced acute cardiomyopathy in rats. Hum Exp Toxicol 2011; 30: 102-109.

33 Chen S, Noguchi Y, Izumida T, Tatebe J, Katayama S. A comparison of the hypotensive and hypoglycaemic actions of an angiotensin converting enzyme inhibitor, an ATla antagonist and troglitazone. J Hypertens 1996; 14: 1325-1330.

34 Furuhashi M, Ura N, Takizawa H, Yoshida D, Moniwa N, Murakami H, Higashiura K Shimamoto K. Blockade of the renin-angiotensin system decreases adipocyte size with improvement in insulin sensitivity. J Hypertens 2004; 22: 1977-1982.

35 Guo Q, Mori T, Jiang Y, Hu C, Ohsaki Y, Yoneki Y, Nakamichi T, Ogawa S, Sato H, Ito S. Losartan modulates muscular capillary density and reverses thiazide diuretic-exacerbated insulin resistance in fructose-fed rats. Hypertens Res 2012; 35: 48-54.

36 Lee MH, Song HK, Ko GJ, Kang YS, Han SY, Han KH, Kim HK, Han JY, Cha DR. Angiotensin receptor blockers improve insulin resistance in type 2 diabetic rats by modulating adipose tissue. Kidney Int 2008; 74: 890-900.

37 Nakagami H. Morishita R. Obesity and gastrointestinal hormones-dual effect of angiotensin II receptor blockade and a partial agonist of PPAR-gamma. Curr Vasc Pharmacol 2011; 9: 162-166.

38 Takai S, Jin D, Miyazaki M. Irbesartan prevents metabolic syndrome in rats via activation of peroxisome proliferator-activated receptor gamma. J Pharmacol Sci 2011 116: 309-315.

Supplementary Information accompanies the paper on Hypertension Research website (http://www.nature.com/hr) 